\title{
Cross-sectional study of retroperitoneal hematoma after invasive intervention in a Chinese population: Prevalence, characteristics, management and outcomes
}

\author{
YONG-GANG SUI, SI-YONG TENG, JIE QIAN, YUAN WU, KE-FEI DOU, \\ YI-DA TANG, SHU-BIN QIAO and YONG-JIAN WU \\ Department of Cardiology, National Center for Cardiovascular Diseases, Fuwai Hospital, \\ Chinese Academy of Medical Sciences and Peking Union Medical College, Beijing 100037, P.R. China
}

Received June 3, 2019; Accepted December 11, 2019

DOI: $10.3892 /$ etm.2020.9040

\begin{abstract}
The present study aimed to explore the clinical characteristics and management of retroperitoneal hematoma (RPH) after invasive intervention during a 12-year period in China. A retrospective review of patients with RPH after various invasive interventions was conducted at the China National Center for Cardiovascular Diseases. A total of 42 patients with a mean age of $63.1 \pm 2.5$ years were continuously recruited in the study between January 2007 and September 2018. The incidence, manifestations and management of RPH were analyzed. A total of 20 patients had punctures in the femoral arterial access under the inguinal ligament and 5 patients had punctures above the inguinal ligament. The majority of RPH occurred within $24 \mathrm{~h}$ after intervention, while some occurred after postoperative $24 \mathrm{~h}$. Pain was the most common symptom in patients with RPH. All patients who underwent intervention presented a reduction in hemoglobin (HB) concentration. The overall incidence of nosocomial infection was $38.1 \%$ and mortality was $7.1 \%$. The findings demonstrated that RPH is a rare complication after invasive intervention of cardiovascular diseases with non-specific clinical manifestations. The reduction of HB concentration was a vital manifestation for RPH. Most RPH cases could be treated by conservative treatment and blood transfusion. A puncture in the femoral arterial access under the inguinal ligament may result in RPH.
\end{abstract}

Correspondence to: Dr Yong-Jian Wu, Department of Cardiology, National Center for Cardiovascular Diseases, Fuwai Hospital, Chinese Academy of Medical Sciences and Peking Union Medical College, 167 North Lishi Road, Xicheng, Beijing 100037, P.R. China E-mail: wuyongjianwork@163.com

Key words: retroperitoneal hematoma, invasive intervention, percutaneous coronary intervention, clinical characteristics

\section{Introduction}

As a new minimally invasive treatment, interventional therapy has been widely used in the treatment of various diseases $(1,2)$, including cardiovascular disease $(3,4)$. Among them, femoral artery puncture is a common approach for cardiovascular disease diagnosis and treatment (5). However, the complications related to femoral artery puncture receive little attention, especially retroperitoneal hematoma (RPH) (6). RPH is an extremely rare, but the most serious and potentially fatal complication of percutaneous intervention (7-10). Recently, with the increasing use of interventional therapy, the morbidity and mortality caused by RPH continues to rise (11). As described in a number of previous reports, the incidence of RPH ranged from 0.15 to $6 \%$ in the world $(10,12,13)$ and the mortality rate reached $4 \%$ (14).

Generally, because the retroperitoneal space could accommodate large amounts of blood, the early clinical manifestations of RPH are relatively indistinct until hypovolemia occurs (15). Therefore, RPH is often delayed in diagnosis, thus increasing the risk of mortality and leading to a potentially fatal outcome. To date, clinical characteristics of RPH after percutaneous intervention have not been systematically reported. Moreover, the optimal treatment of patients with RPH after intervention has not been well defined. Though the characteristics, management, and outcomes of RPH have been previously reported (16), little evidence has focused on RPH after percutaneous intervention. Most related publications were single case reports or small case-based series, which only reported RPH after percutaneous coronary intervention (PCI) $(7,10)$. Moreover, the above studies were reported several years ago and few Chinese cases were studied. Therefore, it is essential to describe and summarize the clinical characteristics of RPH for its diagnosis in China.

A retrospective cross-sectional study of patients with RPH in the past 12 years was conducted at the China National Center for Cardiovascular Diseases. The incidence, clinical characteristics and management of patients with RPH after various percutaneous interventions were analyzed. The potential risk factors of RPH were also explored. 


\section{Materials and methods}

Study population. The retrospective cross-sectional study was performed at the China National Center for Cardiovascular Diseases (Beijing, China). A total of 42 patients with RPH after various interventional therapies were recruited from January 2007 to September 2018. Clinical data were retrospectively assessed by searching hospital diagnosis records and surgical and imaging databases. All patients were diagnosed by imaging and followed up after 1 year to evaluate the outcomes. The research was approved by the Ethics Committee of Fuwai Hospital, National Center for Cardiovascular Diseases, Chinese Academy of Medical Sciences and Peking Union Medical College (Beijing, China). All written consents from patients were waived due to the retrospective nature of the current study.

All patients with RPH were divided into three groups based on methods of interventional therapy. The groups were as follows: PCI group, peripheral artery intervention (PAI) group and other methods (OM) group. OM included atrial fibrillation ablation (AFA), percutaneous transluminal septal myocardial ablation (PTSMA), atrial septal defect closure (ASDC), intra-aortic balloon pump (IABP) and coronary angiography (CA).

Data collection. Detailed characteristics and clinical data of all patients were retrospectively collected from medical records, imaging, diagnosis records and surgical records. The recorded data included patient demographics, admission time, history of disease, methods of interventional therapy, laboratory values, clinical presentation, medical and surgical management, in-hospital clinical events and prognosis.

Baseline data, including age, sex, weight, height, body mass index (BMI), history of disease, intervention methods and puncture site were analyzed to evaluate the relationship between patients' characteristics and RPH occurrence and to explore the risk factors of RPH occurrence. Laboratory values, including creatinine levels, ejection fraction (EF), average heart rate, blood pressure and hemoglobin (HB) concentration were collected from diagnosis records to evaluate the renal and cardiac function, and other functional indicators. Among them, the lowest HB concentration was defined as the lowest detection value from multiple re-examinations of whole blood cell counting during hospitalization. Clinical presentation information was collected for analysis of typical RPH symptoms. The time course of $\mathrm{RPH}$, patient managements and outcome were collected to investigate the optimal approach for RPH diagnosis and treatment.

Statistical analysis. Statistical analysis was performed using SPSS 17.0 software (SPSS, Inc.). Quantitative data are presented as the mean $\pm \mathrm{SD}$. Comparisons of quantitative data among three groups were performed by one-way ANOVA followed by LSD test. Qualitative data were presented as numbers or percentages and compared by $\chi^{2}$ or Mann-Whitney $\mathrm{U}$ test, as appropriate. $\mathrm{P}<0.05$ was considered to indicate a statistically significant difference.

\section{Results}

Distribution of patients. A total of 42 patients were enrolled in the cross-sectional study between 2007 and 2019. During three of those 12 years, relatively more patients were enrolled, 10 of which were recruited in 2017, 4 in 2014 and 4 in 2015 (Fig. 1A). The number of patients with RPH varied with the type of intervention. As shown in Fig. 1B, RPH occurred in 23 patients after PCI, accounting for $54.7 \%$ of all patients. Among them, three cases (7.1\%) received emergency PCI and 20 cases $(47.6 \%)$ received elective PCI. After PAI, 11 patients were diagnosed with RPH, accounting for $26.2 \%$ of all cases. In addition, 8 patients (19.0\%) who underwent OM presented RPH complications (AFA, one case; PTSMA, two cases; ASDC, one case; IABP, one case; CA, three cases).

Baseline demographics. Baseline demographics of patients are listed in Table I.

Epidemiology. All patients had a mean age of $63.1 \pm 2.5$ years and a BMI of $24.6 \pm 0.5 \mathrm{~kg} / \mathrm{m}^{2}$, with $54.8 \%$ female patients $(n=23)$ and $45.2 \%$ male patients $(n=19)$. The PCI group included $11(47.8 \%)$ females and $12(52.2 \%)$ males, with a mean age of $64.3 \pm 2.4$ years and a BMI of $25.0 \pm 0.7 \mathrm{~kg} / \mathrm{m}^{2}$. The PAI group comprised $7(63.6 \%)$ females and $4(36.4 \%)$ males. The mean age and BMI were $59.9 \pm 8.0$ years and $23.4 \pm 1.0 \mathrm{~kg} / \mathrm{m}^{2}$, respectively. For the OM group, 8 patients ( 5 females and 3 males) showed a mean age of $64.6 \pm 7.8$ years and a BMI of $25.0 \pm 0.8 \mathrm{~kg} / \mathrm{m}^{2}$.

Medical history. Of the 42 patients with RPH, $>50 \%$ patients had angina pectoris $(n=22 ; 52.4 \%)$, hypertension $(n=28$; $66.7 \%)$, hyperlipidemia $(\mathrm{n}=33 ; 78.6 \%)$ and coronary artery lesions $(\mathrm{n}=22 ; 52.4 \%)$. Patients who underwent PCI were more likely to have angina pectoris. Patients with ST-segment elevation or non-ST-segment elevation myocardial infarction were more likely to receive PCI.

Laboratory values. The mean value of creatinine levels in 42 patients was $77.7 \pm 4.0 \mu \mathrm{mol} / 1$. The values in three groups were $74.6 \pm 4.5 \mu \mathrm{mol} / 1$ (PCI group), $84.5 \pm 11.3 \mu \mathrm{mol} / 1$ (PAI group) and $77.5 \pm 5.9 \mu \mathrm{mol} / \mathrm{l}$ (OM group).

Data regarding cardiac function were available in all patients with an overall ejection fraction of $59.2 \pm 0.9 \%$. Mean values were $58.3 \pm 1.3 \%$ (PCI group), $62.4 \pm 1.2 \%$ (PAI group) and $57.4 \pm 1.7 \%$ (OM group). The mean heart rate was $72.0 \pm 2.0 \mathrm{bpm}$, ranging from 68.6 to $77.5 \mathrm{bpm}$ between the three groups. Mean systolic and diastolic pressure was $130.4 \pm 4.2$ and $73.5 \pm 2.1 \mathrm{mmHg}$, respectively.

There was no significant difference in laboratory values among the three groups (Table I), except for HB concentration at admission (Fig. 2). HB concentration at admission in the PCI group was significantly lower compared with PAI group $(\mathrm{P}=0.009$, Fig. 2) and OM group ( $\mathrm{P}=0.018$, Fig. 2). However, no significant difference in HB concentration at admission was observed between the PAI and OM groups ( $\mathrm{P}=0.856$, Fig. 2). Notably, the lowest $\mathrm{HB}$ concentrations in the three groups were all significantly decreased (all $\mathrm{P}<0.001$, Fig. 2 ) compared with HB concentration at admission. No significant difference was observed at the lowest HB concentrations among three groups. 


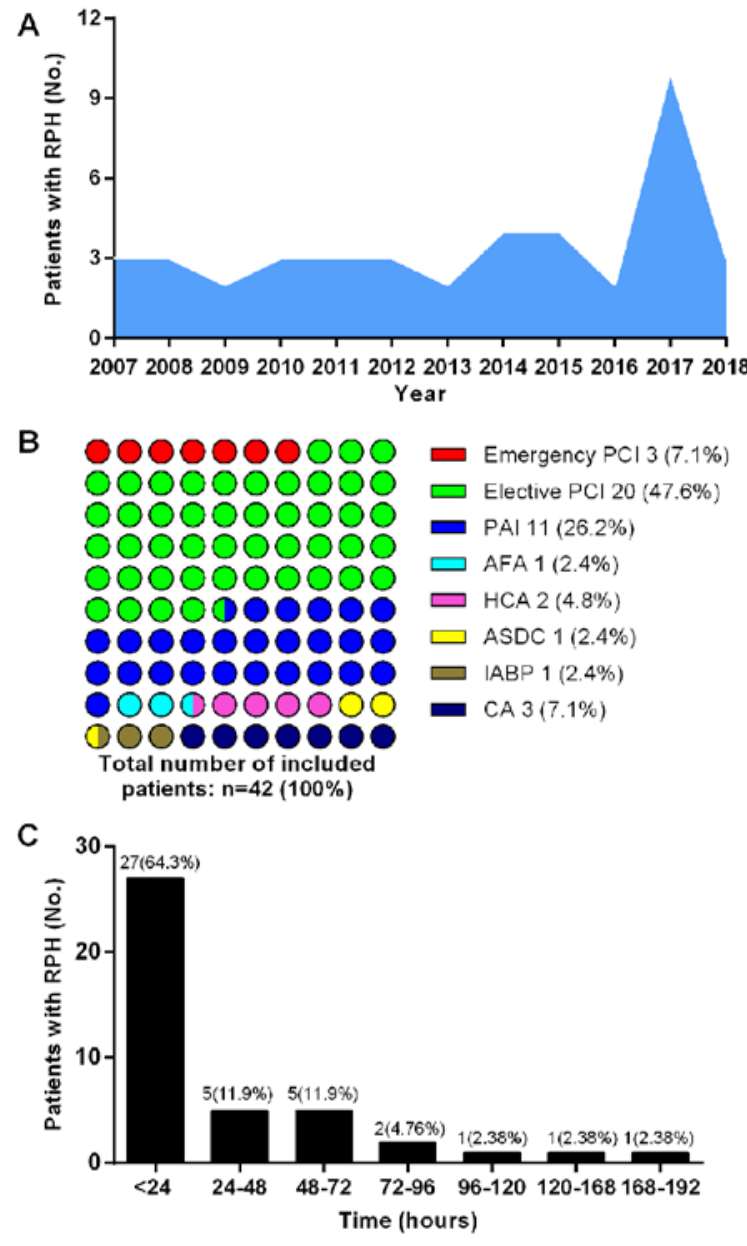

Figure 1. Distribution of patients with RPH. (A) Distribution of patients diagnosed in different years. (B) Distribution of patients with RPH after different interventional therapies. (C) Time interval from procedure conclusion to onset of the first clinical manifestation of RPH. RPH, retroperitoneal hematoma; PCI, percutaneous coronary intervention; PAI, peripheral artery intervention; AFA, atrial fibrillation ablation; PTSMA, percutaneous transluminal septal myocardial ablation; ASDC, atrial septal defect closure; IABP, intra-aortic balloon pump; CA coronary angiography.

Puncture site. Data regarding puncture site were available in 26 patients. A total of 20 cases had punctures in the femoral arterial access under inguinal ligament (PCI, $n=11$; PAI, $n=4$; $\mathrm{OM}, \mathrm{n}=5)$ and 5 cases had punctures above the inguinal ligament (PCI, $n=2$; PAI, $n=3$ ). One case punctured through a transradial approach was diagnosed with spontaneous RPH.

Time course of RPH and clinical presentation. The time course of RPH is shown in Fig. 1C. RPH occurred in 27 $(64.3 \%)$ patients within $24 \mathrm{~h}$ after intervention, followed by 5 cases during postoperative $24-48 \mathrm{~h}(11.9 \%)$ and five cases during postoperative 48-72 h (11.9\%). Overall, $\sim 40 \%$ patients presented RPH after postoperative $24 \mathrm{~h}$. The incidence of RPH decreased with the prolongation of postoperative time.

As shown in Table II, the most common symptom of RPH was pain (42.9\%), with abdominal pain recorded in $8(19.0 \%)$ cases, followed by leg pain in $5(11.9 \%)$ cases, waist pain in 4 $(9.5 \%)$ cases and back pain in $1(2.4 \%)$ case. Another primary symptom was blood pressure reduction, which occurred in $12(28.6 \%)$ cases. In addition, $\sim 15 \%$ of patients presented with sweating, HB reduction and nausea. Other non-specific symptoms included unconsciousness $(9.5 \%)$, dizziness $(7.1 \%)$ and fever (11.9\%).

The common symptoms were generally consistent for different interventional therapies. In the PCI group, $43.5 \%$ patients $(n=10)$ presented with pain, including leg pain, waist pain and abdominal pain, followed by $7(43.5 \%)$ with blood pressure reduction, 4 (7.6\%) with sweating, 4 (7.6\%) with HB reduction, and $4(7.6 \%)$ with fever. Three (7.1\%) PCI patients presented with abdominal distension, unconsciousness and nausea. In the PAI group, the most common symptom of RPH was also pain (4 cases; $36.4 \%$ ), including abdominal pain (1 case), back pain (1 case) and leg pain (2 cases). Four (36.4\%) PAI patients presented with blood pressure reduction and 2 (9.1\%) patients presented with HB reduction. Additionally, each of the patients presented with other symptoms (Table II), including abdominal distension $(1 / 11,9.1 \%)$, sweating $(1 / 11$, $9.1 \%)$, unconsciousness $(1 / 11,9.1 \%)$, dizziness $(1 / 11,9.1 \%)$ and fever $(1 / 11,9.1 \%)$. Similarly, the most common symptom of RPH after OM was also pain (4 cases, 50.0\%), followed by nausea $(25.0 \%)$ and sweating $(25.0 \%)$. No OM patients presented with abdominal distension, unconsciousness, dizziness or fever.

Pre-procedural treatments. A majority of the patients (38/42, $90.5 \%$ ) received preoperative anticoagulation or antiplatelet therapy prior to PCI, PAI and OM. Among all patients, 37 $(88.1 \%)$ patients were administrated with oral aspirin, 32 (76.2\%) were administered with plavix and 15 (35.7\%) were administered with low molecular heparin. A small number of patients were administrated with ticagrelor (5 cases; $11.9 \%$ ) and rivaroxaban (15 cases; $2.4 \%$ ). The pre-operative anticoagulation or antiplatelet therapies for patients are shown in Table III.

Management. Patient management for RPH cases is shown in Table IV. Among all patients with RPH, $81.0 \%$ of patients $(n=34)$ received conservative medical treatment and blood transfusion. Regardless of the type of intervention received, the most common management was conservative medical treatment, including supplement of Ringer's solution, the administration of dopamine, norepinephrine or other vasopressive agents (PCI, 82.6\%; PAI, 72.7\%; OM, 87.5\%) and blood transfusion (PCI, 78.3\%; PAI, 90.9\%; OM, 75.0\%). A total of 3 cases with RPH required emergency surgery, including 1 case from the PCI group and 2 cases from the PAI group. Additionally, elective operation and balloon compression were performed in 2 cases. A spring ring was placed in 1 case in the OM group.

In-hospital outcomes. The prognosis of patients with RPH is summarized in Table V. The overall incidence of nosocomial infection was $38.1 \%$. The incidence of nosocomial infection in patients with RPH after PCI, PAI and OM was $68.8,18.8$ and $12.5 \%$, respectively. The overall mortality of RPH patients was 7.1\%. Among them, 2 cases received PAI treatment and one case received OM. A total of $38(90.5 \%)$ patients showed improvement and were discharged. One case following PCI was transferred to a general hospital. 
Table I. Baseline demographics of patients.

\begin{tabular}{|c|c|c|c|c|}
\hline Index & Total $(n=42)$ & PCI (n=23) & PAI $(n=11)$ & $\mathrm{OM}(\mathrm{n}=8)$ \\
\hline \multicolumn{5}{|l|}{$\operatorname{Sex}(n, \%)$} \\
\hline Female & $23(54.8)$ & $11(47.8)$ & $7(30.4)$ & $5(21.7)$ \\
\hline Male & $19(45.2)$ & $12(63.2)$ & $4(21.1)$ & $3(21.1)$ \\
\hline Age (years) & $63.1 \pm 2.5$ & $64.3 \pm 2.4$ & $59.9 \pm 8.0$ & $64.6 \pm 7.8$ \\
\hline Height (cm) & $163.7 \pm 9.6$ & $162.1 \pm 9.3$ & $167.2 \pm 10.6$ & $163.4 \pm 8.9$ \\
\hline Body weight (kg) & $66.2 \pm 1.6$ & $66.5 \pm 2.4$ & $65.1 \pm 2.7$ & $66.6 \pm 3.0$ \\
\hline $\operatorname{BMI}\left(\mathrm{kg} / \mathrm{m}^{2}\right)$ & $24.6 \pm 0.5$ & $25.0 \pm 0.7$ & $23.4 \pm 1.0$ & $25.0 \pm 0.8$ \\
\hline \multicolumn{5}{|l|}{ Smoking (n, \%) } \\
\hline No & 25 & $11(44.0)$ & $8(32.0)$ & $6(24.0)$ \\
\hline Yes & 17 & $12(70.6)$ & $3(17.7)$ & $2(11.8)$ \\
\hline \multicolumn{5}{|l|}{ STEMI $(\mathrm{n}, \%)$} \\
\hline No & 38 & $20(52.6)$ & $11(29.0)$ & $7(18.4)$ \\
\hline Yes & 4 & $3(75.0)$ & $0(0.0)$ & $1(25.0)$ \\
\hline \multicolumn{5}{|l|}{ NSTEMI (n, \%) } \\
\hline No & 38 & $19(50.0)$ & $11(29.0)$ & $8(21.0)$ \\
\hline Yes & 4 & $4(100.0)$ & $0(0.0)$ & $0(0.0)$ \\
\hline \multicolumn{5}{|c|}{ Angina pectoris (n, \%) } \\
\hline No & 20 & $12(60.0)$ & $6(30.0)$ & $2(10.0)$ \\
\hline Yes & 22 & $11(50.0)$ & $5(22.7)$ & $6(27.3)$ \\
\hline \multicolumn{5}{|l|}{ Hypertension (n, \%) } \\
\hline No & 14 & 4 (28.6) & $7(50.0)$ & $3(21.4)$ \\
\hline Yes & 28 & $19(67.9)$ & $4(14.3)$ & $5(17.9)$ \\
\hline \multicolumn{5}{|l|}{ Diabetes (n, \%) } \\
\hline No & 30 & $16(53.3)$ & $8(26.7)$ & $6(20.0)$ \\
\hline Yes & 12 & $7(58.3)$ & $3(25.0)$ & $2(16.7)$ \\
\hline \multicolumn{5}{|c|}{ Hyperlipidemia (n, \%) } \\
\hline No & 9 & $4(44.4)$ & $3(33.3)$ & $2(22.2)$ \\
\hline Yes & 33 & $19(57.6)$ & $8(24.2)$ & $6(18.2)$ \\
\hline \multicolumn{5}{|l|}{$\operatorname{PAD}(\mathrm{n}, \%)$} \\
\hline No & 27 & $16(59.3)$ & $6(22.2)$ & $5(18.5)$ \\
\hline Yes & 15 & 7 (46.7) & $5(33.3)$ & $3(20.0)$ \\
\hline \multicolumn{5}{|c|}{ Peripheral disease $(\mathrm{n}, \%)$} \\
\hline No & 27 & $16(59.3)$ & $6(22.2)$ & $5(18.5)$ \\
\hline Yes & 15 & 7 (46.7) & $5(33.3)$ & $3(20.0)$ \\
\hline \multicolumn{5}{|l|}{ OMI (n, \%) } \\
\hline No & 39 & $22(56.4)$ & $10(25.6)$ & $7(18.0)$ \\
\hline Yes & 3 & $1(33.3)$ & $1(33.3)$ & $1(33.3)$ \\
\hline \multicolumn{5}{|c|}{ Renal insufficiency (n, \%) } \\
\hline No & 39 & $22(56.4)$ & $9(23.1)$ & $8(20.5)$ \\
\hline Yes & 3 & $1(33.3)$ & $2(66.7)$ & $0(0.0)$ \\
\hline \multicolumn{5}{|c|}{ Atrial fibrillation (n, \%) } \\
\hline No & 40 & $22(55.0)$ & $11(27.5)$ & $7(17.5)$ \\
\hline Yes & 2 & $1(50.0)$ & $0(0.0)$ & $1(50.0)$ \\
\hline \multicolumn{5}{|c|}{ PCI postoperative $(\mathrm{n}, \%)$} \\
\hline No & 36 & $20(55.6)$ & $9(25.0)$ & $7(19.4)$ \\
\hline Yes & 6 & $3(50.0)$ & $2(33.3)$ & $1(16.7)$ \\
\hline \multicolumn{5}{|c|}{ CABG postoperative $(\mathrm{n}, \%)$} \\
\hline No & 38 & $20(52.6)$ & $11(29.0)$ & $7(18.4)$ \\
\hline Yes & 4 & $3(75.0)$ & $0(0.0)$ & $1(25.0)$ \\
\hline
\end{tabular}


Table I. Continued.

\begin{tabular}{|c|c|c|c|c|}
\hline Index & Total $(n=42)$ & PCI $(n=23)$ & PAI $(n=11)$ & $\mathrm{OM}(\mathrm{n}=8)$ \\
\hline \multicolumn{5}{|l|}{ Hypothyroidism (n, \%) } \\
\hline No & 41 & $22(53.7)$ & $11(26.8)$ & $8(19.5)$ \\
\hline Yes & 1 & $1(100.0)$ & $0(0.0)$ & $0(0.0)$ \\
\hline \multicolumn{5}{|l|}{ OCI $(n, \%)$} \\
\hline No & 38 & $19(50.0)$ & $11(28.9)$ & $8(21.1)$ \\
\hline Yes & 4 & $4(100.0)$ & $0(0.0)$ & $0(0.0)$ \\
\hline \multicolumn{5}{|l|}{ Cardiogenic shock (n, \%) } \\
\hline No & 41 & $22(53.7)$ & $11(26.8)$ & $8(19.5)$ \\
\hline Yes & 1 & $1(100.0)$ & $0(0.0)$ & $0(0.0)$ \\
\hline \multicolumn{5}{|c|}{ Left main coronary artery $(\mathrm{n}, \%)$} \\
\hline No & 35 & $18(51.4)$ & $9(25.7)$ & $8(22.9)$ \\
\hline Yes & 7 & $5(71.4)$ & $2(28.6)$ & $0(0.0)$ \\
\hline \multicolumn{5}{|c|}{ Cardiac functional grading $(\mathrm{n}, \%)$} \\
\hline I & 41 & $22(53.7)$ & $11(26.8)$ & $8(19.5)$ \\
\hline IV & 1 & $1(100.0)$ & $0(0.0)$ & $0(0.0)$ \\
\hline \multicolumn{5}{|l|}{ Coronary artery lesions (n, \%) } \\
\hline 0 & 20 & $10(50.0)$ & $7(35.0)$ & $3(15.0)$ \\
\hline 1 & 4 & $3(75.0)$ & $0(0.0)$ & $1(25.0)$ \\
\hline 2 & 6 & $3(50.0)$ & $2(33.3)$ & $1(16.7)$ \\
\hline 3 & 12 & $7(58.3)$ & $2(16.7)$ & $3(25.0)$ \\
\hline \multicolumn{5}{|l|}{ Puncture site (n, \%) } \\
\hline Without radiography & 16 & $9(56.3)$ & $4(25.0)$ & $3(18.8)$ \\
\hline Transradial approach & 1 & $1(100.0)$ & $0(0.0)$ & $0(0.0)$ \\
\hline Above the inguinal ligament & 5 & $2(40.0)$ & $3(60.0)$ & $0(0.0)$ \\
\hline Below the inguinal ligament & 20 & $11(55.0)$ & $4(20.0)$ & $5(25.0)$ \\
\hline Creatinine $(\mu \mathrm{mol} / \mathrm{l})$ & $77.7 \pm 4.0$ & $74.6 \pm 4.5$ & $84.5 \pm 11.3$ & $77.5 \pm 5.9$ \\
\hline Ejection Fraction (\%) & $59.2 \pm 0.9$ & $58.3 \pm 1.3$ & $62.4 \pm 1.2$ & $57.4 \pm 1.7$ \\
\hline Heart rate $(\mathrm{bpm})$ & $72.0 \pm 2.0$ & $68.6 \pm 2.6$ & $77.5 \pm 4.0$ & $74.0 \pm 4.8$ \\
\hline $\mathrm{SBP}$ at admission $(\mathrm{mmHg})$ & $130.4 \pm 4.2$ & $132.1 \pm 6.3$ & $133.6 \pm 8.4$ & $121.1 \pm 5.1$ \\
\hline DBP at admission (mmHg) & $73.5 \pm 2.1$ & $72.3 \pm 2.9$ & $75.9 \pm 4.5$ & $73.8 \pm 3.5$ \\
\hline
\end{tabular}

PCI, percutaneous coronary intervention; PAI, peripheral artery intervention; OM, BMI, body mass index; STEMI, ST-segment elevation myocardial infarction; NSTEMI, non-ST-segment elevation myocardial infarction; PAD, peripheral arterial disease; OMI, old myocardial infarction; OCI, old cerebral infarction; CABG, coronary artery bypass grafting; SBP, systolic pressure; DBP, diastolic pressure; HB, hemoglobin.

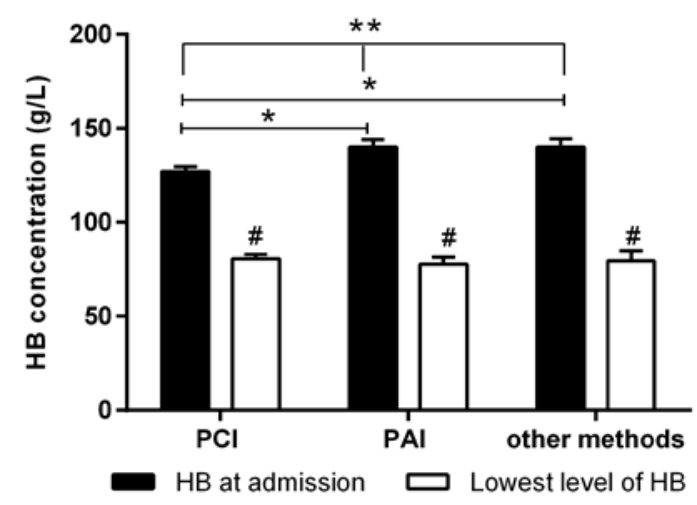

Figure 2. HB concentration in groups PCI, PAI and OM. ${ }^{*} \mathrm{P}<0.05,{ }^{* *} \mathrm{P}<0.001$ (comparison between groups) ${ }^{\#} \mathrm{P}<0.001$ vs. HB at admission. PCI, percutaneous coronary intervention; PAI, peripheral artery intervention; OM, other methods; HB, hemoglobin B.

\section{Discussion}

Although RPH is a rare complication of invasive intervention, it is often associated with high mortality $(1,15)$, which makes prompt diagnosis and treatment essential. However, clinical manifestations vary from pain to shock, thereby the indistinct early manifestations of RPH often lead to delayed treatment (12). To the best of our knowledge, only a few studies about RPH have been reported, whilst no studies involving the Chinese population have been previously carried out. Therefore, it is particularly important to provide more clinical evidence for the diagnosis of RPH among the Chinese population. In the current study, 42 patients who received invasive intervention in the past 12 years were retrospectively and continuously studied. 
Table II. Signs and symptoms presented by patients.

\begin{tabular}{|c|c|c|c|c|}
\hline Index & Total $(n=42)$ & $\mathrm{PCI}(\mathrm{n}=23)$ & PAI $(n=11)$ & $\mathrm{OM}(\mathrm{n}=8)$ \\
\hline \multicolumn{5}{|c|}{ Leg pain $(n, \%)$} \\
\hline No & $37(88.1)$ & $21(91.3)$ & $9(81.8)$ & $7(87.5)$ \\
\hline Yes & $5(11.9)$ & $2(8.7)$ & $2(18.2)$ & $1(12.5)$ \\
\hline \multicolumn{5}{|c|}{ Waist pain (n, \%) } \\
\hline No & $38(90.5)$ & $20(87.0)$ & $11(100.0)$ & $7(87.5)$ \\
\hline Yes & $4(9.5)$ & $3(13.0)$ & $0(0.0)$ & $1(12.5)$ \\
\hline \multicolumn{5}{|c|}{ Abdominal pain (n, \%) } \\
\hline No & $34(81.0)$ & $18(78.3)$ & $10(90.9)$ & $6(75.0)$ \\
\hline Yes & $8(19.0)$ & $5(21.7)$ & $1(9.1)$ & $2(25.0)$ \\
\hline \multicolumn{5}{|c|}{ Back pain (n, \%) } \\
\hline No & $41(97.6)$ & $23(100.0)$ & $10(90.9)$ & $8(100.0)$ \\
\hline Yes & $1(2.4)$ & $0(0.0)$ & $1(9.1)$ & $0(0.0)$ \\
\hline \multicolumn{5}{|c|}{ Abdominal distension (n, \%) } \\
\hline No & $38(90.5)$ & $20(87.0)$ & $10(90.9)$ & $8(100.0)$ \\
\hline Yes & $4(9.5)$ & $3(13.0)$ & $1(9.1)$ & $0(0.0)$ \\
\hline \multicolumn{5}{|c|}{ Nausea } \\
\hline No & $36(85.7)$ & $20(87.0)$ & $10(90.9)$ & $6(75.0)$ \\
\hline Yes & $6(14.3)$ & $3(13.0)$ & $1(9.1)$ & $2(25.0)$ \\
\hline \multicolumn{5}{|c|}{ Sweating (n, \%) } \\
\hline No & $35(83.3)$ & $19(82.6)$ & $10(90.9)$ & $6(75.0)$ \\
\hline Yes & $7(16.7)$ & $4(17.4)$ & $1(9.1)$ & $2(25.0)$ \\
\hline \multicolumn{5}{|c|}{ Unconsciousness (n, \%) } \\
\hline No & $38(90.5)$ & $20(87.0)$ & $10(90.9)$ & $8(100.0)$ \\
\hline Yes & $4(9.5)$ & $3(13.0)$ & $1(9.1)$ & $0(0.0)$ \\
\hline \multicolumn{5}{|c|}{ Dizziness (n, \%) } \\
\hline No & $39(92.9)$ & $21(91.3)$ & $10(90.9)$ & $8(100.0)$ \\
\hline Yes & $3(7.1)$ & $2(8.7)$ & $1(9.1)$ & $0(0.0)$ \\
\hline \multicolumn{5}{|c|}{ Blood pressure reduction $(\mathrm{n}, \%)$} \\
\hline No & $30(71.4)$ & $16(69.6)$ & $7(63.6)$ & $7(87.5)$ \\
\hline Yes & $12(28.6)$ & $7(30.4)$ & $4(36.4)$ & $1(12.5)$ \\
\hline \multicolumn{5}{|c|}{ HB reduction at admission $(\mathrm{n}, \%)$} \\
\hline No & $35(83.3)$ & $19(82.6)$ & $9(81.8)$ & $7(87.5)$ \\
\hline Yes & $7(16.7)$ & $4(17.4)$ & $2(18.2)$ & $1(12.5)$ \\
\hline \multicolumn{5}{|c|}{ Fever (n, \%) } \\
\hline No & $37(88.1)$ & $19(82.6)$ & $10(90.9)$ & $8(100.0)$ \\
\hline Yes & $5(11.9)$ & $4(17.4)$ & $1(9.1)$ & $0(0.0)$ \\
\hline
\end{tabular}

PCI, percutaneous coronary intervention; PAI, peripheral artery intervention; OM, other methods; HB, hemoglobin.

The current study demonstrated that RPH is an uncommon complication from interventions, which is in accordance with previous reports $(7,17)$. Notably, intervention-related $\mathrm{RPH}$ appears to have a high mortality rate of $7.1 \%$. This is partly due to the loss of intravascular volume caused by massive bleeding in the retroperitoneum. Another reasoning behind this is that the increase in abdominal pressure may lead to intra-abdominal organ injury $(18,19)$.

The majority of patients with RPH in the present study after intervention were the elderly (age range, 64-80 years), similar with the majority of cases with spontaneous RPH (16). One possible explanation is that age is a risk factor for bleeding during treatment with anticoagulants such as heparin (20). In the current study, although no significant difference was found, the number of female patients with RPH included in the present study was higher compared with males. Previous reports revealed that female gender was identified as an independent predictor of RPH $(12,14)$. This suggests that additional attention should be focused on the risk of postoperative RPH in female patients. Although several hypotheses 
Table III. Preoperative anticoagulant therapy for patients with RPH.

\begin{tabular}{|c|c|c|c|c|}
\hline Index & Total $(n=42)$ & PCI $(n=23)$ & PAI $(n=11)$ & $\mathrm{OM}(\mathrm{n}=8)$ \\
\hline \multicolumn{5}{|c|}{ Low molecular heparin $(\mathrm{n}, \%)$} \\
\hline No & 27 & $12(44.4)$ & $8(29.6)$ & $7(25.9)$ \\
\hline Yes & 15 & $11(73.3)$ & $3(20.0)$ & $1(6.7)$ \\
\hline \multicolumn{5}{|c|}{ Aspirin $(\mathrm{n}, \%)$} \\
\hline No & 5 & $1(20.0)$ & $2(40.0)$ & $2(40.0)$ \\
\hline Yes & 37 & $22(59.5)$ & $9(24.3)$ & $6(16.2)$ \\
\hline \multicolumn{5}{|c|}{ Plavix $(\mathrm{n}, \%)$} \\
\hline No & 10 & $3(30.0)$ & $4(40.0)$ & $3(30.0)$ \\
\hline Yes & 32 & $20(62.5)$ & $7(21.9)$ & $5(15.6)$ \\
\hline \multicolumn{5}{|c|}{ Ticagrelor (n, \%) } \\
\hline No & 37 & $20(54.1)$ & $10(27.0)$ & $7(18.9)$ \\
\hline Yes & 5 & $3(60.0)$ & $1(20.0)$ & $1(20.0)$ \\
\hline \multicolumn{5}{|c|}{ Rivaroxaban (n, \%) } \\
\hline No & 41 & $23(56.1)$ & $11(26.8)$ & $7(17.1)$ \\
\hline Yes & 1 & $0(0.0)$ & $0(0.0)$ & $1(100.0)$ \\
\hline
\end{tabular}

RPH, retroperitoneal hematoma; PCI, percutaneous coronary intervention; PAI, peripheral artery intervention; OM, other methods.

Table IV. Clinical treatment for patients with RPH.

\begin{tabular}{|c|c|c|c|c|}
\hline Treatment & Total $(n=42)$ & PCI $(n=23)$ & $\operatorname{PAI}(\mathrm{n}=11)$ & $\mathrm{OM}(\mathrm{n}=8)$ \\
\hline \multicolumn{5}{|c|}{ Emergency surgery (n, \%) } \\
\hline No & 39 & $22(56.4)$ & $9(23.1)$ & $8(20.5)$ \\
\hline Yes & 3 & $1(33.3)$ & $2(66.7)$ & $0(0.0)$ \\
\hline \multicolumn{5}{|c|}{ Elective operation $(\mathrm{n}, \%)$} \\
\hline No & 40 & $21(52.5)$ & $11(27.5)$ & $8(20.0)$ \\
\hline Yes & 2 & $2(100.0)$ & $0(0.0)$ & $0(0.0)$ \\
\hline \multicolumn{5}{|c|}{ Balloon compression $(\mathrm{n}, \%)$} \\
\hline No & 40 & $22(55.0)$ & $10(25.0)$ & $8(20.0)$ \\
\hline Yes & 2 & $1(50.0)$ & $1(50.0)$ & $0(0.0)$ \\
\hline \multicolumn{5}{|c|}{ Spring ring $(\mathrm{n}, \%)$} \\
\hline No & 41 & $23(56.1)$ & $11(26.8)$ & $7(17.1)$ \\
\hline Yes & 1 & $0(0.0)$ & $0(0.0)$ & $1(100.0)$ \\
\hline \multicolumn{5}{|c|}{ Conservative medical management $(\mathrm{n}, \%)$} \\
\hline No & 8 & $4(50.0)$ & $3(37.50)$ & $1(12.5)$ \\
\hline Yes & 34 & $19(55.9)$ & $8(23.53)$ & $7(20.6)$ \\
\hline \multicolumn{5}{|c|}{ Blood transfusion } \\
\hline No & 8 & $5(62.5)$ & $1(12.5)$ & $2(25.0)$ \\
\hline Yes & 34 & $18(52.9)$ & $10(29.4)$ & $6(17.6)$ \\
\hline
\end{tabular}

RPH, retroperitoneal hematoma; PCI, percutaneous coronary intervention; PAI, peripheral artery intervention; OM, other methods.

have been proposed, the reason for this association remains unclear. Previous reports hypothesized that different arterial mechanical properties, smaller common femoral artery dimensions and estrogen-related arterial structures in females may increase the need for multiple arterial punctures and risk of bleeding $(9,17)$. One of the aforementioned reasons may have led to the difference in RPH occurrence between sexes. In summary, the findings indicated that age and sex may be potential risk factors for RPH.

RPH mostly occurred within $24 \mathrm{~h}$ after intervention and in patients with hypertension. Although the correlation has not been clarified, these results indicated that patients 
Table V. Adverse events and prognosis of patients with RPH.

\begin{tabular}{lcccc}
\hline Index & Total $(\mathrm{n}=42)$ & PCI $(\mathrm{n}=23)$ & PAI $(\mathrm{n}=11)$ & OM $(\mathrm{n}=8)$ \\
\hline $\begin{array}{l}\text { Nosocomial infection (n, \%) } \\
\text { No }\end{array}$ & 26 & $12(46.2)$ & $8(30.8)$ & $6(23.1)$ \\
Yes & 16 & $11(68.8)$ & $3(18.8)$ & $2(12.5)$ \\
Prognosis (n, \%) & & & & \\
Death & 3 & $0(0.0)$ & $2(66.7)$ & $1(33.3)$ \\
Transfer & 1 & $1(100.0)$ & $0(0.0)$ & $0(0.0)$ \\
Discharge & 38 & $22(57.9)$ & $9(23.7)$ & $7(18.4)$ \\
\hline
\end{tabular}

RPH, retroperitoneal hematoma; PCI, percutaneous coronary intervention; PAI, peripheral artery intervention; OM, other methods.

receiving interventional therapy should be closely monitored for the occurrence of RPH within $24 \mathrm{~h}$, particularly patients with a history of hypertension. Notably, several patients did not develop RPH until several days after intervention. Thus, patients should also be alert to the occurrence of RPH within one week after intervention if they feel uncomfortable. Farouque et al (12) previously reported the time course of $\mathrm{RPH}$; however, only short-term RPH incidence within a few hours after intervention was reported. Approximately $75 \%$ of cases presented with RPH within the first $3 \mathrm{~h}$ after conclusion of the procedure. Therefore, the present study demonstrated that RPH might also occur after a number of post-procedural days.

Another important finding was that 20 patients with RPH had punctures in the femoral arterial access under the inguinal ligament while only 5 patients had punctures above the inguinal ligament. The result indicated that RPH might occur in patients who underwent a femoral artery puncture either below or above the inguinal ligaments, which was inconsistent with results from previous reports $(10,12,21)$. Farouque et al (12) indicated that a higher femoral artery puncture site was a significant risk factor for RPH. Similarly, Levine et al (10) and Selivanov et al (21) found an increased risk of vascular complications with femoral access at or above the most inferior border of the inferior epigastric artery. However, the present study demonstrated that punctures under the inguinal ligament could also cause RPH. Similarly in a previous study, $45 \%$ of patients with RPH had a sheath insertion in the common femoral artery well below the inguinal ligament (12). The occurrence of RPH may be due to the spread of bleeding from the femoral artery puncture site under the inguinal ligament to the anatomic fascial planes, leading the bleeding into the retroperitoneum. Thus, low femoral artery punctures cannot eliminate the risk of RPH. More importantly, the femoral vascular structures at this location are accessible to effective manual compression, hence manual compression is advised to prevent the occurrence of presumed RPH. More studies with long-term follow-up periods are needed to verify the above hypothesis.

Symptoms of RPH were usually non-specific and atypical, however back and waist discomfort was found to be the most common symptom (16). Among the 42 cases of the present study, abdominal pain was the most common symptom. Moreover, other symptoms such as leg pain, waist pain and abdominal distension also frequently occurred in some patients. These symptoms were also described by Kent et al (8), Farouque et al (12) and Sajnani et al (22), therefore they may be identified as specific signs of RPH. Thus, the present study suggested that the possibility of RPH should be considered in any patients receiving interventional therapy who present with abdominal pain and distension or leg pain. The remaining symptoms of RPH were non-specific clinical manifestations, including nausea, sweating, blood pressure reduction, unconsciousness and dizziness, which were most likely due to reduced volume of blood in the circulatory system as a result of RPH (16). In the present study, common symptoms were generally consistent for the different interventional therapies (PCI, PAI or OM). Subclinical hematoma was not observed after any interventional therapies (17). Additionally, patients with RPH showed lower HB concentrations after percutaneous intervention compared with at admission, suggesting that a reduction in HB concentration may be the most important, sensitive and common manifestation of RPH. Thus, low HB concentration may be a risk factor that predisposed patients to RPH. It is worth noting that seven patients showed decreased HB concentration, but no symptoms of discomfort. Chan-Tack (23) reported that decreasing HB concentration was a sign of RPH in a patient with fatal spontaneous RPH induced by enoxaparin use. Additionally, in a large series study of RPH following cardiac catheterization, a reduction in HB concentration was detected in $96 \%$ of patients (1). One patient with RPH resulting from dual testicular and intra-renal arterial injury also presented lower HB concentrations compared with normal range (24). Whilst the above results suggested that a reduction in HB concentration might be a sign of RPH, this still warrants further verification. Therefore, changes in HB concentration must be serially monitored in real-time in patients undergoing femoral artery puncture. The HB concentration at admission in the PAI group patients was higher compared with the PCI group, but the lowest level was similar. This fact suggested that patients in the PAI group showed a more significant decrease in HB. Thus, for PAI recipients, HB concentrations should be more closely monitored. Overall, RPH has an extraordinarily pleiomorphic presentation. The present findings have provided evidence for the diagnosis of RPH.

Currently, to the best of our knowledge, no studies have focused on optimal therapeutic approaches for patients with $\mathrm{RPH}$, and review of the literature did not provide clear guidance. 
Thereby, clinicians are required to choose and adjust appropriate treatment solutions according to patient status. To date, treatment strategies for RPH are mainly based on small cohort series or isolated case reports. Sajnani et al (22) reported two patients treated by balloon tamponade who demonstrated improved hemodynamics in a controlled environment. Serruys et al (3) reported a case of life-threatening RPH that was successfully treated with balloon occlusion and catheter delivery of thrombin. Embolization using the combination of coils, gelatin and/or polyvinyl alcohol has been successfully used for RPH. Microcoil embolization has also been used to stop bleeding for RPH patients $(18,25)$. Additionally, González et al (5) reported three cases of RPH that were successfully treated with fluid transfusion and reversal of anticoagulation. Blood transfusion has also been successfully used as RPH treatment in a study by Kwok et al (26). In the present study, most patients received conservative medical treatment and blood transfusion, some of which have also undergone emergency surgery. If the hemodynamics and $\mathrm{HB}$ concentration of patients remained stable after fluid infusion or transfusion, conservative treatment could be performed, otherwise surgical occlusion or balloon occlusion was required. The current findings provide more evidence that conservative management, such as blood transfusion, intensive care unit monitoring, vigorous fluid resuscitation and reversal of anticoagulation, were effective for most patients with RPH $(9,16,22)$. Stopping bleeding in time can also prevent the mortality caused by RPH, although optimal approaches need to be further explored.

The present study reported several important findings. Firstly, a 12-year review among Chinese population with RPH could evaluate practice and long-term outcomes. Secondly, systematic evidence for RPH after various invasive interventions provides new insights for the occurrence time of complications arising from RPH. Thirdly, the current study revealed that any femoral artery puncture may cause the occurrence of RPH, even if only one of the invasive interventions was performed. Fourthly, a higher incidence of RPH was observed when the puncture site was below the inguinal ligament compared with puncture sites above the inguinal ligament. Finally, a reduction in HB concentration may be an important sign of RPH. Patients with low HB concentration should be subjected to an abdominal CT scan immediately to prevent RPH occurrence.

There were also several limitations in the present study. Firstly, the current study is a cross-sectional observational and a retrospective study. The quality of data mainly depended on the accuracy of medical records. Secondly, the epidemiological characteristics of RPH cannot accurately infer causality, due to an undefined prevalence of RPH caused by PCI, PAI or OM. To reduce the above limitations, a long-term follow-up was conducted from 2007 to 2018 in the current study.

In conclusion, RPH is an infrequent complication of invasive intervention with non-specific clinical manifestations. A puncture in femoral arterial access under the inguinal ligament may also result in RPH. RPH mostly occurred within $24 \mathrm{~h}$ after interventions, especially in the patients with hypertension. The most common symptom was pain, and a reduction in $\mathrm{HB}$ concentration was an important RPH manifestation. Conservative medical treatment and blood transfusion were suitable for the majority of RPH patients, and emergency surgery was also required in selected cases. Future studies are needed to determine the optimal strategy for managing patients with a high risk of RPH.

\section{Acknowledgements}

Not applicable.

\section{Funding}

No funding was received.

\section{Availability of data and materials}

The datasets used and/or analyzed during the present study are available from the corresponding author on reasonable request.

\section{Authors' contributions}

YGS, YJW and SYT conceived and designed the study. JQ, YW and KFD measured patient hemoglobin concentrations. YDT and SBQ performed data acquisition. SYT and JQ performed data analysis and interpretation. YGS wrote the first draft of the manuscript. All authors read and approved the final manuscript.

\section{Ethics approval and consent to participate}

Ethics approval was obtained from the Ethics Committee of Fuwai Hospital, National Center for Cardiovascular Diseases, Chinese Academy of Medical Sciences and Peking Union Medical College (Beijing, China). All written consents from patients were waived due to the retrospective nature of the current study.

\section{Patient consent for publication}

Not applicable.

\section{Competing interests}

The authors declare that they have no competing interests.

\section{References}

1. Frank JJ, Kamalakannan D, Kodenchery M, Savoy-Moore RT and Rosman H: Retroperitoneal hematoma in patients undergoing cardiac catheterization. J Interv Cardiol 23: 569-574, 2010.

2. Livraghi T, Solbiati L, Meloni MF, Gazelle GS, Halpern EF and Goldberg SN: Treatment of focal liver tumors with percutaneous radio-frequency ablation: Complications encountered in a multicenter study. Radiology 226: 441-451, 2003.

3. Serruys PW, Morice MC, Kappetein AP, Colombo A, Holmes DR, Mack MJ, Ståhle E, Feldman TE, van den Brand M, Bass EJ, et al: Percutaneous coronary intervention versus coronary-artery bypass grafting for severe coronary artery disease. N Engl J Med 360: 961-972, 2009.

4. Kornowski R, Mehran R, Dangas G, Nikolsky E, Assali A, Claessen BE, Gersh BJ, Wong SC, Witzenbichler B, Guagliumi G, et al: Prognostic impact of staged versus 'One-Time' multivessel percutaneous intervention in acute myocardial infarction: Analysis from the HORIZONS-AMI (harmonizing outcomes with revascularization and stents in acute myocardial infarction) trial. J Am Coll Cardiol 58: 704-711, 2011. 
5. González C, Penado S, Llata L, Valero C and Riancho JA: The clinical spectrum of retroperitoneal hematoma in anticoagulated patients. Medicine (Baltimore) 82: 257-262, 2003.

6. Moscucci M, Mansour KA, Kent KC, Kuntz RE, Senerchia C, Baim DS and Carrozza JP Jr: Peripheral vascular complications of directional coronary atherectomy and stenting: Predictors, management, and outcome. Am J Cardiol 74: 448-453, 1994.

7. Akkus NI, Beedupalli J and Varma J: Retroperitoneal hematoma: An unexpected complication during intervention on an occluded superficial femoral artery via a retrograde popliteal artery approach. Rev Port Cardiol 32: 623-627, 2013.

8. Kent KC, Moscucci M, Mansour KA, DiMattia S, Gallagher S, Kuntz R and Skillman JJ: Retroperitoneal hematoma after cardiac catheterization: Prevalence, risk factors, and optimal management. J Vasc Surg 20: 905-913, 1994.

9. Testerman GM, Shilad S and George KJ: Rapid warfarin reversal with factor VIIa in an elderly trauma patient with retroperitoneal hematoma. Tenn Med 102: 37-39, 2009.

10. Levine MN, Raskob G, Landefeld S and Kearon C: Hemorrhagic complications of anticoagulant treatment. Chest 119 (1 Suppl): 108S-121S, 2001.

11. Ulrich MR, Brock DM and Ziskind AA: Analysis of trends in coronary artery bypass grafting and percutaneous coronary intervention rates in Washington state from 1987 to 2001. Am J Cardiol 92: 836-839, 2003.

12. Farouque HM, Tremmel JA, Raissi Shabari F, Aggarwal M Fearon WF, Ng MK, Rezaee M, Yeung AC and Lee DP: Risk factors for the development of retroperitoneal hematoma after percutaneous coronary intervention in the era of glycoprotein IIb/IIIa inhibitors and vascular closure devices. J Am Coll Cardiol 45: 363-368, 2005.

13. Waksman R, King SB III, Douglas JS, Shen Y, Ewing H, Mueller L, Ghazzal ZM and Weintraub WS: Predictors of groin complications after balloon and new-device coronary intervention. Am J Cardiol 75: 886-889, 1995.

14. Tremmel JA, Tibayan YD, O'Loughlin AJ, Chan T, Fearon WF, Yeung AC and Lee DP: Most accurate definition of a high femoral artery puncture: Aiming to better predict retroperitoneal hematoma in percutaneous coronary intervention. Catheter Cardiovasc Interv 80: 37-42, 2012.

15. Baylis SM, Lansing EH and Glas WW: Traumatic retroperitoneal hematoma. Am J Surg 103: 477-480, 1962.

16. Sunga KL, Bellolio MF, Gilmore RM and Cabrera D: Spontaneous retroperitoneal hematoma: Etiology, characteristics, management, and outcome. J Emerg Med 43: e157-e161, 2012.
17. Trimarchi S, Smith DE, Share D, Jani SM, O'Donnell M, McNamara R, Riba A, Kline-Rogers E, Gurm HS and Moscucci M; BMC2 Registry: Retroperitoneal hematoma after percutaneous coronary intervention: Prevalence, risk factors, management, outcomes, and predictors of mortality: A report from the BMC2 (Blue Cross Blue Shield of Michigan Cardiovascular Consortium) registry. JACC Cardiovasc Interv 3: 845-850, 2010

18. Campbell NR, Hull RD, Brant R, Hogan DB, Pineo GF and Raskob GE: Aging and heparin-related bleeding. Arch Intern Med 156: 857-860, 1996.

19. French JT, Goins B, Saenz M, Li S, Garcia-Rojas X, Phillips WT, Otto RA and Bao A: Interventional therapy of head and neck cancer with lipid nanoparticle-carried rhenium 186 radionuclide. J Vasc Interv Radiol 21: 1271-1279, 2010.

20. Jacques $T$ and Lee R: Improvement of renal function after relief of raised intra-abdominal pressure due to traumatic retroperitoneal haematoma. Anaesth Intensive Care 16: 478-482, 1988.

21. Selivanov V, Chi HS, Alverdy JC, Morris JA Jr and Sheldon GF: Mortality in retroperitoneal hematoma. J Trauma 24: 1022-1027, 1984.

22. Sajnani N and Bogart DB: Retroperitoneal hemorrhage as a complication of percutaneous intervention: Report of 2 cases and review of the literature. Open Cardiovasc Med J 7: 16-22, 2013.

23. Chan-Tack KM: Fatal spontaneous retroperitoneal hematoma secondary to enoxaparin. South Med J 96: 58-60, 2003.

24. Ahmed M, Keshava SN, Moses V and Valson AT: Endovascular management of a large retroperitoneal haemorrhage resulting from dual testicular and intra-renal arterial injury after renal biopsy. Indian J Radiol Imaging 28: 362-365, 2018.

25. Sreeram S, Lumsden AB, Miller JS, Salam AA, Dodson TF and Smith RB: Retroperitoneal hematoma following femoral arterial catheterization: A serious and often fatal complication. Am Surg 59: 94-98, 1993.

26. Kwok CS, Kontopantelis E, Kinnaird T, Potts J, Rashid M Shoaib A, Nolan J, Bagur R, de Belder MA, Ludman P, et al: Retroperitoneal hemorrhage after percutaneous coronary intervention: Incidence, determinants, and outcomes as recorded by the british cardiovascular intervention society. Circ Cardiovase Interv 11: e005866, 2018.

(i) $\ominus$ This work is licensed under a Creative Commons Attribution-NonCommercial-NoDerivatives 4.0 International (CC BY-NC-ND 4.0) License. 